\title{
Integrating Challenge Based Learning Into a Smart Learning Environment: Findings From a Mobile Application Development Course
}

\author{
Rafael Chanin, Alan R. Santos, Nicolas Nascimento, Afonso Sales, Leandro Pompermaier and Rafael Prikladnicki \\ Pontifical Catholic University of Rio Grande do Sul, School of Technology \\ Av. Ipiranga 6681, Porto Alegre, Brazil, CEP: 90619-900 \\ \{rafael.chanin, alan.santos, nicolas.nascimento, afonso.sales, leandro.pompermaier, rafaelp\}@pucrs.br
}

\begin{abstract}
Training students on mobile application development inherits the challenges of teaching software engineering where the target computer is a device that has a large number of features accessible by software. Furthermore, the most related experience in teaching students reveals difficulties in developing software engineering competencies. In this paper we present results from an iOS course held in a smart learning environment that adopted the Challenge Based Learning framework as the teaching methodology. Our results indicate that combining an active methodology along with an engaging environment can foster and improve software development learning.
\end{abstract}

Keywords-Smart Learning Environments, Challenge Based Learning, Mobile Software Development, Teaching.

\section{INTRODUCTION}

Active learning methodologies like Problem-Based Learning, Project-Based Learning (PBL) and Challenge Based Learning $(\mathrm{CBL})$ engage students and improve their performance. These approaches moves students to a different role when compared to traditional classes, engaging students in real problems [6]. In this study, we focus on the use of CBL in a smart learning environment. CBL enables students to conduct research by integrating practices with theory and application of knowledge and skills, such as collaboration and problem solving, and taking action in the community context [5].

Moreover, the educational context is changing due to the advancements in technology [4]. Tradicional classes, often perceive as formal, passive, and not engaging, have been slowly replaced by student-centric approaches. This new way of perceiving education, combining active methodologies, technology and modern infrastructure has led to the creation of the term "Smart Lerning Environments" [3].

In this sense, this paper presents findings from a 6-weeks mobile application development course that uses CBL as a teaching methodology. Our preliminary results indicate that applying a pro-active pedagogy framework that fosters collaboration and personalized learning within a smart learning environment can be beneficial to students.

The remainder of this paper is organized as follows. Section II presents the background on smart learning en-

DOI reference number: 10.18293/SEKE2018-058 vironments. In Section III the concept of Challenge Based Learning is explained and, in Section IV, we describe the mobile application course in detail. Section V depicts the methodology used in this research. In Section VI we present our preliminary results and, finally, we draw our conclusion and future works in Section VII.

\section{SMART LEARNING ENVIRONMENTS}

There are several definitions for Smart Learning Environments (SLE) in the literature. However, in the context of this paper, we use the one from Koper [3], which is "physical environments that are enriched with digital, context-aware and adaptive devices, to promote better and faster learning". Even though the word "smart" relates to the use of smart technologies, the main goal of a SLE is to provide learning guidance and all the necessary infrastructure to make the learning process effective, efficient and engaging [2].

One of the main goals of a SLE is to meet the educational needs from current students. Tradicional classes, in which instructors are in the center of the process and students do not actively participate, have been replaced by approaches that foster collaboration, action and engagement. However, in order to effectively implement this change, not only the physical environment needs to be adapted, but also instructors need to put in place a different teaching methodology [4].

In this new context, instructors are no longer the only source of knowledge. Similarly, students are not only knowledge consumers. In fact, the roles of instructors and students may become less distinct and could be interchangeable [4].

\section{Challenge-BASED LEARNING}

Experiential learning is the source of a variety of learning frameworks that are used all over the world. Problem-Based Learning, Project-Based Learning, Task-Based Learning and Challenge Based Learning are just a few examples of these frameworks. "The foundations of experiential learning can be found within the history of most cultures, but were formally organized and presented by David Kolb drawing heavily on the works of John Dewey and Jean Piaget" [6]. Challenge Based Learning (CBL) [5] is a learning framework based on solving real world challenges. 
The CBL process begins with the definition of a big idea, which is a broad concept that can be explored in several ways. The big idea has to be engaging and important to students and society. Once the big idea is chosen and the essential question is created, the challenge is defined. From this point, students must come up with the guiding questions and guiding activities and resources, which will guide them to develop a successful solution. The next step is analysis, which will set the foundation for the definition of the solution. Once the solution is agreed upon, the implementation begins. Finally, evaluation is undertaken in order to check out the whole process and verify if the solution can be refined.

\section{THE COURSE}

The course curriculum applied in this work can be divided into two portions: iOS Programming and User Experience. All participants received CBL training and were required to dedicate 20 hours per week during six weeks. The learning was facilitated by instructors, which had different levels of industry and academic experience. All instructors had previous iOS development training and CBL training, and more than four years experience. In addition, the course was held in a smart learning environment, which provided not only all necessary equipment, but also a modern infrastructure that allow students to be creative and comfortable during the learning process.

TABLE I. Classes ACtivities

\begin{tabular}{|c|c|c|}
\hline Class & Activities & Deliverable \\
\hline 1 & $\begin{array}{l}\text { Equipment assignment to students. Student's and } \\
\text { Instructors presentations. Quick introduction to } \\
\text { important tools and shortcuts. }\end{array}$ & Reflection \\
\hline 2 & $\begin{array}{l}\text { Introduction to Coding, Introduction to Story- } \\
\text { boards, UILabel and UIButton. }\end{array}$ & Exercise \\
\hline 3 & $\begin{array}{l}\text { UIView, UIViewController and the Model-View- } \\
\text { Controller (MVC) paradigm. }\end{array}$ & Exercise \\
\hline 4 & $\begin{array}{l}\text { Introduction to UX (User-Experience) in iOS, Per- } \\
\text { sonas and Paper Prototyping. }\end{array}$ & Exercise \\
\hline 5 & UIImageView, UIPicker, UIDatePicker. & Exercise \\
\hline 6 & $\begin{array}{l}\text { Navigation using multiple ViewControllers, } \\
\text { UINavigationController and UITabBarController. }\end{array}$ & Exercise \\
\hline 7 & UISlider and UIScrollView. & Exercise \\
\hline 8 & Challenge Based Learning. & $\begin{array}{l}\text { CBL Process Do- } \\
\text { cumentation }\end{array}$ \\
\hline 9 & AutoLayout. & Exercise \\
\hline 10 & UITableView and Nano-Challenge. & None \\
\hline 11 & Nano-Challenge Development and Deliver. & $\begin{array}{l}\text { Nano-Challenge } \\
\text { Solution }\end{array}$ \\
\hline 12 & UserDefaults and CoreData. & Exercise \\
\hline 13 & Design Guidelines. & Exercise \\
\hline 14 & MapKit. & Exercise \\
\hline 15 & Mini-Challenge - Engage. & None \\
\hline $16-17$ & Mini-Challenge - Investigate. & None \\
\hline $18-29$ & Mini-Challenge - Act. & None \\
\hline 30 & Mini-Challenge Presentations. & $\begin{array}{l}\text { Mini-Challenge } \\
\text { Solution Keynote, } \\
\text { Reflection }\end{array}$ \\
\hline
\end{tabular}

The deliverables described in Table I are related to items used for students development and assessment as described by Nichols et al. [5]:

- Reflection: It is a video, audio or text file where students reflect on the content and on the process. As described in [5]: "Much of the deepest learning takes place by considering the process, thinking about one's learning, and analyzing ongoing relationships between the content and concepts.".

- Exercise: Students are encourage to follow a development rule (such as using a specific framework) but are free to increment the solution and to develop it.

- CBL Documentation: During the course, learners produce contents using text, video, audio and pictures. These artifacts are helpful, as they expose information of the learning process. These can serve many uses, such as reflections, assessments, evidence of learning, portfolios and for telling the story of their challenges.

- Nano-Challenge: One type of CBL activity. These are shorter in length, focused on a particular content area or skill, have tight boundaries and are guided by the instructor. Both Big Idea and Essential Question are provided to the students. The process includes some level of investigation, but at a lower level of intensity and often stop short of implementation with an external audience.

- Mini-Challenge: Another type of CBL activity. It has a longer duration (2-4 weeks) and allows learners to start with a Big Idea and work using the entire framework. The research depth and the reach of their solutions increases and the focus can be content specific or multidisciplinary. Mini-Challenges are good for intense learning experiences that stretch learners and prepare them for longer challenges.

\section{Methodology}

The research methodology for this study was based on a process proposed by Eisenhardt [1]. The proposed research question was: "Can mobile application development be more effectively learn if taught in a smart learning environment using an active methodology, such as Challenge Based Learning?". The rationale behind this question was to find out whether students can take advantage of the environment as well as of the methodology in order to better learn the content.

\section{A. Data Collection \& Analysis}

Throughout the course, we collected several data regarding students deliverables. In addition, we conducted a survey with all students that have completed the course described in Section IV. In total, 25 students were interviewed. All questions were open-ended and focused on the following areas: (i) teaching environment; (ii) teaching methodology; (iii) content; and (iv) instructors.

Once all data was collected, we grouped and categorized the information. It is important to point out that part of our evaluation was based on data collected from students. In order to mitigate eventual flaws during data collection, the interviews were conducted by two people that did not directly participate in the course.

\section{RESULTS}

We found indicatives that the combination of an innovative environment with an active learning methodology was key to the success of the course. Students felt engaged and motivated to learn and even to go beyond the course content. 
Regarding the environment, $90 \%$ of the students emphasized how impressed they were when they first enter the classroom. The infrastructure, a coworking space equipped with comfortable and adjustable chairs and tables and several spaces to brainstorm and to sketch ideas, not only provided everything students needed, but it was also inspiring.

One key point the final survey allowed us to perceive was regarding the teaching methodology. Some of the students reported feeling uncomfortable with the dynamics used in class at first, as the lecturing (where the instructor would present the content) was not long and the students were quickly given a challenge. However, as the course progressed, they understood that this approach was beneficial, as they reported being more engaged with the content.

None of the students knew Challenge Based Learning prior to the course. Nonetheless, all of them pointed out that the methodology was key to keep them focused and engaged throughout the course. Several students, however, mentioned that the methodology could have been introduced in the first week of the course. As can be noticed in Table I, CBL was only presented to students on the 8th class.

The Mini-Challenge delivered and presented at the end of the course proved (according to the evaluation of the instructors) that students learned the content. Even though some students mentioned that having one or two more weeks would be beneficial to the learning process, they were all able to create a complete mobile application, with some having developed features that were not even covered during classes, such as Speech Recognition.

Regarding the instructors, $50 \%$ of the students pointed out that the different teaching styles was a problem. For example, while one instructor explained a specific content in detail, the other chose to give just a quick overview and then let students search for other information. In total, four instructors participated in the course. It became clear that it was not necessary to have that many instructors in this course.

Another set of data collected was students' deliverables. A Delivered task (85\%) is one that is completed in terms of scope, quality and deadline. A Partially Delivered task $(2 \%)$ is one that fail in scope, quality or deadline. Finally, a Not Delivered task (13\%) is one that was not delivered. The evaluation for each task was made by at least two instructors.

This information was somehow intriguing to the authors, since they understood that having $13 \%$ of the tasks not delivered was too much. By analysing task by task (see Fig. 1) it can be seen that tasks 10 and 11 are the outliers. By talking to the instructors, we found out that since students were performing really well, they decided to raise the bar after task 9. It turned out that almost half of the students were not able even to partially deliver these challenges.

A lesson learned about this approach is that to push students in order to see where they can get can be good. However, this needs to be strategically done in order not to disengage students. For instance, a given challenge can have three different achievement levels (for example, bronze, silver and gold). By doing so, not only instructors can measure how far students can go, but it also keeps students motivated into achieving the highest level.

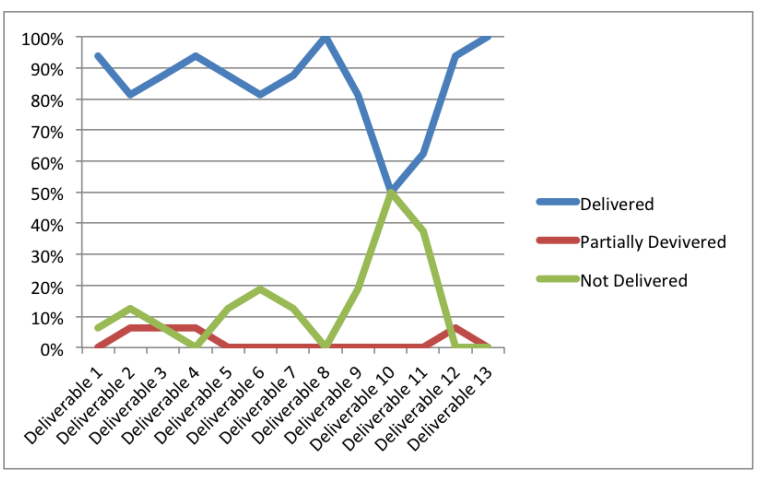

Fig. 1. Deliverables During the Course

\section{CONCLUSION AND FUtURE WORK}

The traditional educational landscape is changing to a more pro-active and collaborative one. In this scenario, instructors also need to adapt themselves in order to better help students throughout the learning process.

This work presented a case study that represents this new trend. We provided findings from a mobile application development course that took advantage of a modern environment, new technologies, and a pro-active teaching methodology Challenge Based Learning. Our results, although preliminary, reveal that students in fact learn and engage more when they are put in the center of the learning process. Moreover, the use of challenges kept students motivated to find solutions, which makes the learning process more fun and less tedious.

As future work we intend to monitor and evaluate more courses in similar contexts that the one presented in this paper. In addition, we are planning to extend the duration of the course from six to eight weeks in order to give more time for the students to practice the concepts learned as well as more time in the Mini-Challenge activity to develop a more robust mobile application.

\section{ACKNOWLEDGMENTS}

This project is partially funded by FAPERGS, project 17/2551-0001/205-4.

\section{REFERENCES}

[1] K. Eisenhardt. Building theories from case study research. Academy of management review, 14(4):532-550, 1989.

[2] B. Gros. The design of smart educational environments. Smart Learning Environments, 3(1):1-11, 2016.

[3] R. Koper. Conditions for effective smart learning environments. Smart Learning Environments, 1(1):1-17, 2014.

[4] J. Ng, D. Ruta, A. Al Rubaie, D. Wang, L. Powell, B. Hirsch, L. Ming, C. Ling, and A. Al Dhanhani. Smart learning for the next generation education environment. In 2014 International Conference on Intelligent Environments, pages 333-340. IEEE, 2014.

[5] M. Nichols, K. Cator, and M. Torres. Challenge Based Learning Guide. Digital Promise, Redwood City, CA, USA, 2016.

[6] A.R. Santos, A. Sales, P. Fernandes, and M. Nichols. Combining Challenge-Based Learning and Scrum Framework for Mobile Application Development. In Proceedings of the 2015 ACM Conference on Innovation and Technology in Computer Science Education (ITiCSE'15), pages 189-194, Vilnius, Lithuania, July 2015. 